\title{
Racismo y escuela en México: Reconociendo la tragedia para intentar la salida
}

\section{Racism and Schools in Mexico: Seeking a Solution by Recognizing the Tragedy}

DOI: https://doi.org/10.32870/dse.v0i13.241

\section{Saúl Velasco Cruz* \\ Bruno Baronnet**}

Gallo, caballo y mujer, por su raza

has de escoger.

(Refrán mexicano

«anónimo» o popular).

No tiene la culpa el indio, sino el que lo hace compadre.

(Otro refrán mexicano muy popular).

Resumen: El racismo de la sociedad mexicana se reproduce en la escuela por medio de los contenidos curriculares y de las prácticas que en sus recintos tienen lugar cotidianamente. Erradicarlo es un imperativo social demandado por los grupos sociales que históricamente han sido afectados por el fenómeno. Sin embargo, este interés no se ha demostrado como un propósito serio desde las políticas educativas, porque el racismo ha resultado muy conveniente para las relaciones de poder que sostienen el orden social existente. Por ello, sin olvidar esta circunstancia, en este ensayo nos hemos propuesto identificar y definir posibles vías que pudieran ayudar a los actores educativos, fundamentalmente a los profesores, a emprender acciones antirracistas concretas. Palabras clave: racismo, educación y racismo, educación básica, educación indígena, formación docente, antirracismo.

\begin{abstract}
Racism in Mexican society is reproduced through curricular content and everyday practices in schools. Its elimination is a social imperative demanded by historically discriminated groups. Nonetheless, this demand has not translated into significant educational policy because racism is very convenient for power relations that maintain the current social order. In this context we propose in this essay to identify and define possible avenues towards helping educational actors, primarily teachers, engage in concrete antiracist activity. Key words: racism, education and racism, K-12 education, Indigenous education, teacher training, antiracism
\end{abstract}

\section{Introducción}

La sociedad mexicana es una sociedad de refranes. Para quienes no lo saben, en ellos se transmiten consejos, modos de pensar, maneras de ser y formas de entender el mundo. Para abreviar, esto mismo se puede decir y entender en un refrán, "los dichos de los viejos son evangelios chiquitos". Los evangelios no se discuten, se asumen. Los refranes son el reflejo de una manera de pensar am-

* Sociólogo. Profesor investigador en la Universidad Pedagógica Nacional, Unidad Ajusco, México. SNı nivel 1. Miembro del grupo: "Educación, interculturalidad y racismo", de la Red de Investigación Interdisciplinaria sobre Identidades, Racismo y Xenofobia (Red INTEGRA), apoyada por Conacyt. Correo electrónico: velascosaul@gmail.com

** Sociólogo. Profesor investigador en el Instituto de Investigaciones en Educación, Universidad Veracruzana, Xalapa, Veracruz. SNI nivel 2. Coordinador del grupo "Educación, interculturalidad y racismo" de la red INTEGRA. Correo electrónico: bruno.baronnet@gmail.com 
pliamente compartida. Aparentemente no tienen temporalidad, nadie sabe cuándo nacieron exactamente como dichos, pero eso no importa. Lo que vale de ellos es, en primer lugar, su mensaje, en segundo lugar, su elocuencia imperativa para normar criterios y, en tercero, su capacidad para demostrar su cumplimiento como promesas que se auto-realizan. De este calibre asumimos que es el racismo de la sociedad mexicana. Un racismo que se asemeja a un refranero completo. Este es el punto de partida en esta contribución. No pretendemos discutir los orígenes del racismo, tan solo los describiremos, para poder nombrar el fenómeno, nada más. Nos interesa aquí dejar claro que no existe un solo racismo, sino algo más que eso.

Los racismos tienen anclas en las escuelas y es entonces que pensamos que vale la pena reconocer esta circunstancia para explorar alguna forma de imaginar su eliminación. Para su exposición, este ensayo de sociología educativa está dividido en seis apartados que desembocan en una conclusión propositiva para pensar en la erradicación del racismo desde las escuelas en México. Después de presentar el carácter estructural de la institucionalización del racismo en la sociedad, abordamos en adelante sus repercusiones en el campo de los procesos curriculares, como una herencia histórica pero también como producto de la jerarquización de aprendizajes escolares que busca medir, clasificar y alterar la "inteligencia" de la niñez. Después de examinar lo que está en juego en la situación particular de la educación indígena en el país, nos preguntaremos si es posible desmontar el racismo y cuáles serían los principales retos emergentes de una escuela dotada de un currículum antirracista.

\section{Racismo estructural o institucional}

Vivimos en una sociedad racista. La premiada actriz keniana, nacida en México, Lupita Nyong'o lo hizo evidente cuando, habiendo alcanzado popularidad por su destacada capacidad histriónica, destapó al mundo, en diciembre de 2015, el racismo mexicano en toda su crudeza. ${ }^{1}$ En la misma época Ali Roxox, estudiante k'iche' de Guatemala, doctorante en un centro de investigación chiapaneco, había revelado a los ojos de la comunidad internacional el racismo en la frontera sureste del país. Denunció cómo había sido virtualmente "echada de una cafetería de San Cristóbal de Las Casas, Chiapas, tras ser confundida con una vendedora ambulante", en virtud de su apariencia indígena. ${ }^{2}$

1 Lupita Nyong'o es ganadora de un premio Oscar por su actuación en la película 12 años de esclavitud. Reveló a la revista francesa de moda Elle que en su juventud había sufrido racismo en México. En sus palabras, ella refiere que mientras radicó, ella y su familia en Taxco, Guerrero, "La atención en la calle era traumatizante. Éramos una rareza. La gente nos paraba y nos tomaba fotos sólo porque éramos negros. Era un momento difícil, durante la adolescencia, cuando estás entrando en ti mismo y tratando de formar tu propio camino, pero estás inseguro donde te encuentras. Eso me devastó". Citado en el periódico electrónico Sin embargo, disponible en: http://www.sinembargo.mx/03-12-2015/1569528 (última visita, 11 de abril de 2016).

$\underline{2}$ Una amiga que la acompañaba, Montserrat Balcorta Sobrino, narraría el hecho de la siguiente manera; "Tan bonito el día hoy y nos acaban de correr de la cafetería-pastelería francesa Oh la la. A Ali Roxox la detuvieron en la puerta prohibiéndole el paso de manera déspota diciéndole que no podía entrar a vender. No ha sido la primera vez que nos pasa. Estoy hasta la chingada de tanta humillación racista y violencia hacia las mujeres indígenas de este pueblo." Citado en la revista Proceso: I. Mandujano (2013). "Echan de una cafetería a indígena estudiante de doctorado tras confundirla con una vendedora ambulante", 13 de abril de 2013 , disponible en: http://www.proceso.com.mx/357788/echan-de-una-cafeteria-a-indigena-estudiante-de-doctorado-tras-confundirla-con-una-vendedora-ambulante. (Última visita, 11 de abril de 2016). 
Quienes la habían expulsado eran empleados del establecimiento; unos jóvenes de la localidad, tal vez de la misma condición (maya) de Ali, pero que por su situación laboral, actuaban como meros vectores de un racismo que yacía instalado en lo más profundo de su subjetividad y que los había conminado, bajo los mecanismos aparentemente autónomos de una decisión propia, vigilante a su vez del orden convencional, normal o normalizado.

Casos como estos, menos o igual de incisivos, o incluso de mayores dimensiones dramáticas, abundan cotidianamente en el país; es decir, que no son meras situaciones excepcionales. México es una sociedad desigual e injusta, pero también es racista, como lo han revelado con datos precisos las encuestas sobre la discriminación del Consejo Nacional para Prevenir la Discriminación (CONAPRED), así como estudios científicos como los desarrollados por Castellanos Guerrero (2003 y 2012), Gall (2004 y 2007), Gómez Izquierdo (2008), Moreno Figueroa (2010), París Pombo (2002), Saldívar (2012), Navarrete (2016), Iturriaga (2011), Menéndez Spina (2001 y 2016) y Urías Horcasitas (2007). Pero, ¿por qué la sociedad mexicana es racista? Proponemos que se debe a razones que se fueron imponiendo en su dilatado diseño institucional. En un corte de larga duración es posible distinguir la influencia que ejercerán distintos episodios históricos, empezando, como ya lo ha explicado impecablemente Aníbal Quijano (2000), primero por la conquista, siguiendo con la colonización, luego por las influencias de los pensamientos occidentales preponderantes en el periodo independiente, e incluso en las iniciativas que terminarán instituyendo a las diferentes versiones que se ensayarán de la sociedad mexicana a lo largo del siglo XIX, y que servirán de algún modo de base fundamental para confirmar y coronar como racista a la sociedad que surgió de la Revolución Mexicana.

De este modo, el racismo que aparecerá orientado por el México mestizo, que defiende José Vasconcelos de una manera elocuente en su libro La raza cósmica (1925), no es de ninguna manera resultado de una inspiración espontánea y unipersonal, sino que representa un producto que acumula y canaliza un conjunto de pulsiones xenofóbicas distendidas que parecen converger por fin, sin subsumirse o mezclarse del todo, en la idea de poder construir explícitamente una sociedad racializada aunque ciertamente diferida. Por un lado, para el Estado, en cuanto al racismo que reviste su proyecto, el derrotero será -al menos desde el discurso- alcanzar la mezcla, que en virtud de postulados ideológicos y políticos ha sido convertida en prototipo e ideal, a condición de que en el orden previsto guiara el faro occidental en todos los sentidos posibles. Para esta posición, el mestizo será -sobre todo a partir de la tercera década del siglo XX-el recurso político por excelencia para alcanzar el ideal de la nueva sociedad que, como en otros contextos del mundo occidental, se inspiraba en una lógica eugenésica, siempre selectiva.

Para las elites criollas, en cambio, el racismo de su interés no variará en absoluto el sentido, pues importaba, como había importado siempre, la preservación de los orígenes, el mantenimiento de la blanquitud; es decir, el pigmento blanco europeo de la piel y el fenotipo, la preservación de los linajes y los privilegios. De forma parecida lo será para las otras elites que ambicionaban los 
privilegios de los criollos, pero con la diferencia de que lo suyo, para decirlo con una idea de F. Navarrete (2016), era un asunto fundamentalmente aspiracional, es decir, de subida, de evidente capilaridad racial, de blanqueamiento súbito o en su defecto, gradual. De este modo, el México mestizo que inventa la Revolución Mexicana encarnaría el ropaje mestizo-céntrico que hace presentable al racismo crudo y duro que ha prevalecido en virtualmente todos los ensayos de la sociedad mexicana, concediendo siempre, y bajo cualquier circunstancia, privilegios a los blancos en detrimento de todos aquellos otros que no lo fueran; aunque ciertamente con gradaciones o escalas de privilegios de clase, que podían significar posiciones intermedias como las que prometía la condición criolla, ladina o mestiza.

\section{Racismo ideal y racismo real en la sociedad y en la educación}

La realidad racista de la sociedad se replica en la escuela. Al considerar que la sociedad mexicana está asolada por el racismo, no perdamos de vista cómo la cuestión del racismo ideal -que postuló y sigue postulando el mestizaje como su derrotero-, se articula con la cuestión más compleja del racismo real que hace convivir a diferentes racismos (como los ya señalados) bajo la sombrilla del racismo de la mestizofilia (Basave, 1992). Pese a la complejidad de la problemática, conviene recordar que los racismos se alimentan de procesos ideológicos y mentales que se sostienen en la creencia de que debiera existir una jerarquización racial de las culturas humanas.

Como fenómeno de naturaleza ideológica, los racismos no surgen por generación espontánea, por tanto, como lo ha señalado T. Van Dijk (2007), es preciso ser enseñado y aprendido, y para ello la educación juega un papel relevante. Allí en donde la educación se manifieste, en todos los espacios y momentos en que ella ocurra, las ideas de corte racista pueden ser enseñadas y a la vez aprendidas; es decir, que circulan en los salones de clase y en los recesos, en los materiales didácticos, en los pizarrones negros y las pantallas electrónicas. Estas ideas penetran también en los auditorios, los pasillos y los cubículos de las instituciones públicas de educación superior, incluyendo las que forman profesionales de la educación, por lo cual se vuelve indispensable investigar e intervenir en contextos universitarios y regionales particulares, como en la Universidad de Guadalajara y en Jalisco (Carlos Fregoso, 2016; Cejas, 2004).

En realidad no prevalece una vía exclusiva de aprendizaje de los prejuicios de superioridad cultural y de clase, aunque la escuela ha resultado hasta ahora un lugar privilegiado en ese propósito. Como lo han documentado algunas investigaciones especializadas (Masferrer, 2012; Saldívar Tanaca, 2012; Velasco Cruz, 2016), hasta ahora el racismo de la mestizofilia, que materializa el racismo ideal, se sigue enseñando en escuelas del nivel básico del país, incluidas aquellas del subsistema de educación indígena. Pese a los cambios y reformas curriculares, más o menos periódicos, los libros de texto gratuitos y comerciales siguen reproduciendo en sus contenidos lecciones impregnadas de caracteres racistas, explícitos e implícitos, que han sido identificadas plenamente. 
De la misma manera, las ideas racistas se traducen en prácticas discriminatorias que imperan en las escuelas de la educación básica.

Esta situación es moneda corriente en las interacciones entre alumnos, y suele ser frecuente en las interacciones entre maestros y alumnos tanto como lo es en la convivencia en el resto de la llamada comunidad escolar. En el auge del uso retórico oficial de la educación intercultural y comunitaria -que declara buscar el reconocimiento y revaloración de todas las culturas originarias del país (y de la existencia de instituciones que fincadas en la ley contra la discriminación deben, por mandato constitucional, velar por su prevención y erradicación)-, la difusión del racismo no ha declinado. Al contrario, como lo han observado los trabajos de J. R. Gnade (2008), D. Hernández Rosete (en prensa) y B. Baronnet (2013), el racismo y las discriminaciones en las escuelas se enraízan en la exacerbación de los desprecios racistas que circulan en la sociedad mexicana.

\section{Racismo confortable y racismo incómodo en la escuela}

Tradicionalmente la educación básica, orientada sobre la base del referente mestizo, procura crear una atmósfera proclive al mismo. De este modo, los mestizos o quienes puedan asumirse o pasar por tales, pueden sentir, en la escuela, cierto confort en ello. Pero no es el caso para todos aquellos otros que escapan a esta condición. La mestizo-conformación que pretende la escuela puede generar cierta xenofobia hacia elites blancas, pero sobre todo tiende a provocar situaciones agraviantes e incómodas en los afromexicanos e indígenas y otros grupos minorizados. Si la mezcla ladina es la regla, todo lo que a ello escape puede pasar al umbral de la anormalidad. Ser blanco en un entorno mestizo ya es motivo de diferenciación, de anormalidad. Es motivo de desprecio en relación con su pertenencia cultural, pero también con su origen social, a través del racismo de clase que opera en las sociedades contemporáneas (Balibar y Wallerstein, 1990). Dado que el racismo mestizofílico no es el único en operación, aunque se defina como el preponderante desde la postura oficial que destaca en los contenidos escolares, lo blanco puede devenir -por razones sociales que desbordan a la escuela- en distinción (como lo opuesto al rechazo), y sin duda muy en ventaja, pero es poco probable que resulte en rechazo como invariablemente ocurre con otras condiciones como lo afro o lo indígena.

De ordinario entendemos la acción de la escuela como un asunto sistemático y organizado, con planes, con contenidos evolutivamente organizados y dosificados en una perspectiva duradera y de largo aliento, por la que ha de pasar el estudiante si quiere realmente vivir un efecto definido como transformador de su vida. Es así que ésta se define como una acción que exige disciplina, constancia para la acreditación de cada una de sus etapas, aunque a menudo no se insista mucho en ello. Precisamente de esta disciplina rutinaria, normativizante, casi fordista, se beneficia el racismo, porque no necesariamente pervive en los contenidos y en la acción de la escuela como una carga de contenidos y de prácticas obligadamente dosificados, aunque sí reiterativos, como los observó Gnade (2008) en sus investigaciones de los contenidos de los libros de texto de la educación primaria indígena. 
Las escuelas, sus planes y programas de estudio y prácticas curriculares en estos niveles, esculpen y modelan de una manera rigurosa personalidades, subjetividades, formas de pensar, de actuar y de sentir. Representan espacios clave de socialización política, con la adquisición de modos de interactuar y de entender el mundo, la idea de orden social y el orden social mismo. Todo ello con un esmero inaudito, bajo los preceptos de un deber ser disciplinado, tenaz, constante que no se arredra y no desmerece por el hecho que de esa misma disciplina y constancia deba surgir, paradójicamente, un esperado espíritu crítico, creativo, innovador y hasta humanista de quienes se ven intervenidos por ellos, es decir, por la escuela y sus contenidos y prácticas.

Aunque parezca contradictorio, todo esto se entiende y acepta como complementario, indispensable y apropiado. Enseñar el orden social, su normalización, puede discurrir en apariencia en armonía con el esmero que busca delinear el intelecto, por incentivar la curiosidad y la sabiduría, o lo que se entienda por ella. Bourdieu (1990) encontraría en esta dupla la acción de lo que va a denominar "el racismo de la inteligencia"; es decir, a través del cual los dominantes justifican su dominación del orden social y se sienten de una esencia superior. Por ello se vuelve crucial analizar cómo las elites sienten que dominan una sociedad fundada en formas de discriminación basadas en la "inteligencia"; es decir, como señala Bourdieu, que está fundada en lo que mide el sistema escolar con el nombre de inteligencia. La jerarquía social generada por el uso de los grados en las pruebas escolares estandarizadas no es tan diferente de la que está basada en el origen social, porque los dominados están siendo predominantemente pobres y no blancos (Croizet, 2013). Esta característica selectiva parece tener buena aceptación en el mundo occidental porque permite legitimar las clasificaciones arbitrarias, reactivando el racismo que deriva de un proceso eugenésico y de darwinismo social que busca a los más aptos y mejor dotados en cuestiones del intelecto fundamentalmente. Las tensiones ligadas a los efectos del racismo en los procesos curriculares y a la desigualdad racial en la educación (McCarthy, 1993) se concretan en México a través de las controversias políticas en torno a la aplicación de pruebas estandarizadas en español en el contexto de la niñez de las escuelas de educación indígena en Chiapas (Klein, 2014), verdaderas fábricas de racismo de la inteligencia.

Pero toda esta acción explícita de la escuela crea, o engendra, sus opuestos. Lo que no quepa en el orden es lo contrario, desorden. Lo que no pueda englobar lo normal está fuera de lugar, puede ser descalificado, combatido, y de ser posible rendido y eliminado. Entonces, en el mejor de los casos, se desconfía de las formas de orden y de vida que son diferentes a las que la escuela tiene como legítimas. A los modos distintos de pensar el mundo les sucede algo semejante. Las culturas, las lenguas, los sistemas de conocimientos que no tienen lugar en lo escolar, entran por principio o como norma, al umbral de lo descalificable. Mientras no suceda algo que los depure, con una limpieza monocultural que los haga complementarios o compatibles con lo escolar o con lo socialmente validado como normal, no tendrán lugar más que en el lado externo, precisamente en el lado de lo excluido y lo negado. Esto es lo regular. Esto es lo que todo escolar teórica o conceptualmente 
debería aprender y dar por válido. Este es el fundamento de la legitimación del racismo de la escuela, de sus contenidos y de sus prácticas.

Lo señalado hasta aquí ha recibido escasa atención por parte de las academias. En general, se encuentran algunos trabajos especializados que abordan el tema educativo Gómez Izquierdo (2005), Molina Ludy (2000), Saldívar Tanaca (2012), Gnade (2008), Masferrer (2012), Hernández Rosete (en prensa), pero la mayoría es reciente y tiene un impacto marginal en la docencia universitaria. No obstante, el déficit de especialización científica se puede complementar con lo que ofrecen otras contribuciones del campo de la sociología, la ciencia política y la antropología, que se han ocupado de estudiar las características discriminatorias de la sociedad y la educación mexicana. Combinando ambas referencias es posible arribar al reconocimiento de que el racismo escolar deriva (ciertamente, en una mirada de largo aliento) del orden de la conquista y la colonia, y del orden que siguió, y que se conoce como el del México independiente, pero sobre todo del proyecto racista del México mestizo que, heredando todo lo anterior, inspiró el diseño institucional de la sociedad resultante del periodo postrevolucionario de 1910. La educación pública corrió con la encomienda de modelar esa sociedad. Y siendo de este modo, al racismo de la educación básica mexicana no se le puede calificar como una falla, como una imperfección del sistema o como una falta interna, intrínseca y desligada del orden englobante que lo contiene. Es todo lo contrario.

El racismo de la educación pública básica es un ingrediente elemental, deliberadamente puesto para lograr un producto específico: la formación de profesionales y ciudadanos de la sociedad mexicana. Anhela forjar una sociedad orgullosa de su pasado indígena y de su herencia española, pero fundidos ambos aspectos en esa figura controvertida e inasible llamada mestizo. Dicho afán lo denomina A. Basave (1992) como mestizofilia, o como sentimiento de preferencia por tal tipo de mezcla. Podría pensarse que tal definición es ahora lejana, pues parece que ha perdido fuerza un tipo de proyecto de unidad nacional de aquel tipo.

Sin embargo, tal planteamiento racista perdura y se mantiene visible hoy en día en los contenidos de la educación primaria y en los propios de la educación secundaria. Gnade nos ofrece un registro meticuloso que demuestra el gran vigor con que los ingredientes racistas persisten en los actuales programas educativos y libros de texto de ambos niveles escolares. Hernández Rosete (en prensa) y Baronnet (2013) en Chiapas argumentan que los imaginarios racistas se visualizan en la práctica docente cotidiana, en las interacciones directas que se verifican en los recintos escolares, así como en las relaciones entre los profesores y las familias.

Los padres, las madres y las autoridades comunitarias están a menudo convocados a realizar faenas y "cooperaciones" materiales. Sin embargo, se les niega la capacidad de intervenir en las formas y contenidos de la enseñanza y su evaluación. El racismo legitima la supuesta incapacidad de los pueblos y barrios en participar en el diseño e implementación de una educación acorde al contexto. En los proyectos de sociedad multicultural y neoliberal se vuelve siempre más aceptable la inhabilitación de las clases populares en decidir y valorar qué tipo de educación reciben sus hijos en la escuela. 
Este plan racista de sociedad encomendado para su realización a la escuela ha sido denunciado en distintas épocas por distinguidos estudiosos críticos del sistema. Lo han hecho antropólogos, sociólogos, politólogos y filósofos mexicanos, o extranjeros interesados en el caso mexicano. La historia también registra que los afectados (principalmente los pueblos indígenas), bajo la figura de agentes y movimientos sociales, sucesivamente han denunciado al racismo del proyecto hegemónico de sociedad encomendado a la escuela pública (Mejía y Sarmiento, 1987). Unos y otros han podido contribuir a comprender que el racismo de la escuela es el continuum del racismo del modelo de sociedad que se sigue defendiendo con amplitud dentro y fuera de la escuela misma. Y esta característica singular también signa a la llamada educación indígena que inventó el régimen posrevolucionario (en la década de 1930) para crear una oferta educativa especial e integradora con su adaptación relativa a las características étnicas y lingüísticas de los pueblos originarios del país.

\section{Racismo en la educación indígena}

Sin que se haya propuesto escribir específicamente sobre el racismo de la educación indígena, E. Ramírez (2006), en su libro Educación indígena en México, revela con énfasis notable la manera en que la propuesta educativa para los pueblos indígenas, creada por el régimen postrevolucionario, mantuvo invariable la marca del racismo que le heredaron casi todos los proyectos, pequeños y grandes, que históricamente se habían ensayado desde la época colonial. Obviamente, de un periodo a otro las maneras fueron cambiando, pero la esencia se mantuvo y se mantiene. En sus contenidos y en sus prácticas el racismo en la educación indígena está activo, al menos así se deriva de las investigaciones que recientemente realizaron en ese campo autores como Gnade, Baronnet, Saldívar Tanaca y Hernández Rosete. El subsistema educativo indígena sumerge, como cualquier otra oferta educativa oficial, a los niños, a los adolescentes y a las culturas de los pueblos, a su sabiduría y a sus cosmovisiones, a los influjos del racismo. Cada aspecto que constituye esta oferta educativa está imbuido de racismo. No hay manera de sustraerlo de ello, por más benevolente que sea la mirada. El uso de la lengua materna, que es una de sus principales características, cuando así sucede, es totalmente sustractivo (Hamel, 2004; Muñoz Cruz, 1987; Rebolledo, 2010). Es decir, se utiliza como mero recurso para facilitar la castellanización, pues el idioma castellano es el que se exige en los subsiguientes niveles educativos. El programa que la dirige es el mismo de la educación general, y a los libros de texto les sucede algo semejante. Los maestros que en teoría deben dominar la lengua de sus estudiantes, a veces la hablan y están ubicados en escuelas de comunidades de su variante lingüística, pero en otras situaciones su desempeño se realiza en comunidades en donde se habla una lengua distinta. No todos son profesores de carrera (Velasco Cruz, 2015). Lo usual ha sido que se conviertan en docentes mediante un breve curso de dos meses que los induce a la docencia (Jordá Hernández, 2000). Aun cuando los datos censales, desde hace décadas, ubican a las familias indígenas en las cabeceras municipales, en los polos de desarrollo agropecuario y en las ciudades, la oferta educativa indígena sigue siendo eminentemente rural. Además, los profeso- 
res de la educación indígena, como lo observó Hernández Rosete (en prensa) en sus indagaciones, perpetran el racismo en sus interacciones con los niños y niñas.

En la década de 1970, algunos profesores del subsistema de educación indígena, organizados en figuras como la Alianza Nacional de Profesionales Indígenas Bilingües, Asociación Civil (ANPIBAC), denunciaban las fallas que le observaban al mismo (Mejía y Sarmiento, 1987); entre ellas figuraban claramente las relativas al racismo. Stefano Varese y algunos otros estudiosos de los temas indígenas y educativos que participaban en el proyecto llamado culturas populares, hacían algo semejante (Pérez Ruiz y Argueta, 2015). Destacados intelectuales indígenas de las décadas de 1980 y 1990 también se pronunciaron al respecto. La educación indígena comenzaría entonces a experimentar algunos cambios formales; fue denominada bilingüe, luego bilingüe bicultural y, finalmente, intercultural bilingüe. Sin embargo, el racismo que la ha acompañado siempre no fue nunca eliminado. Gnade (2008), en su investigación de tesis doctoral, encontró al racismo en los contenidos de los libros de texto de la educación indígena totalmente vivo, en plena era de la educación intercultural. Estos hallazgos coinciden con los resultados de análisis de las discriminaciones racistas en la educación de la población negra latinoamericana en países como Brasil (Gallo, 2014) y Colombia (Mena, 2011), en los cuales se evidencia el papel del Estado en las violaciones a la dignidad humana.

\section{¿Es posible desmontar el racismo?}

En la década de 1990, en el mundo académico aparecieron numerosos estudios que sugerían la conveniencia de adoptar planteamientos interculturales para contrarrestar y abatir el racismo en la educación. Tesis como esas alimentaron el debate que orientaría a la educación indígena a convertirse, al menos nominalmente, como ya se ha señalado, en una opción intercultural. Argumentos semejantes alcanzarían al resto de la educación básica que al inicio de la primera década del siglo XXI terminó por definirse como una opción intercultural. Sus promotores, como S. Schmelkes, se apuraron a llamar a este proceso como el de la interculturalidad para todos. Libros, ensayos, artículos, conferencias, congresos y ponencias conferían posibilidades de cambio. Y sí hubo cambios. Se crearon instituciones a nivel federal (CGEIB, INALI) dotadas de grupos de trabajo que editaron investigaciones, manuales multilingües y una variedad de cuadernos de trabajo interculturales que salieron de las imprentas oficiales.

En la era del interculturalismo institucionalizado en el discurso oficial pero casi ausente en la práctica docente, hasta el racismo es sujeto de innovación. De tener preponderantemente un cariz fundado en la raza pasó de súbito a tener a la cultura como variante racializada. A la educación intercultural le debemos el relanzamiento del racismo, pero ahora como racismo cultural. El racismo cultural es más reciente, corresponde a la época que se abrió unas décadas antes del fin de la guerra fría, pero se hizo mayormente notable cuando tal acontecimiento fue consumado. Wieviorka (2009), en su libro Racismo, una introducción, explica este cambio como una declinación 
del racismo de la raza. Sin embargo, parece que el racismo de la raza no fue sustituido, coexiste, imperturbable, junto con el racismo de la cultura.

Frente a resultados como estos, algunos han pensado que la interculturalidad en la educación parece haber agotado su promesa y estar de salida, puesto que no está logrando los efectos positivos que proponen sus postulados (Díaz-Couder y Gigante, 2015). Otras lecturas, en cambio, consideran que aún es posible encontrar en este tipo de enfoque educativo lo necesario para contravenir y desmontar el racismo en la educación, siempre y cuando se rompa con los límites que entraña la propuesta oficial de la misma. Entonces, bajo su faro, se ensayan diseños alternativos dentro del propio sistema educativo oficial. En Oaxaca, por iniciativa propia, algunos profesores se declaran sujetos con capacidad de agencia, y bajo un juego de palabras altamente simbólico proceden a tomar la escuela (que hay que aclarar es el nombre de su proyecto autogestionario) con el propósito de convertirla en una institución al servicio de las comunidades, con lo cual parecen decididos a contravenir el influjo hegemónico y racista del programa educativo nacional.

En el estado de Michoacán, algunas escuelas, por decisión acordada entre profesores, padres de familia y asambleas comunitarias, están haciendo algo semejante (Hamel, 2004). En otros casos, las iniciativas son de otro signo. No cancelan posibilidades al enfoque intercultural y comunitario pero su repercusión directa toma distancia con las pretensiones del sistema educativo nacional. Es el caso de las alternativas de educación para la autonomía como las que desarrollan las escuelas de las comunidades zapatistas en Chiapas (Baronnet, 2013). Aunque la heterogeneidad sea parte de su característica, todos estos casos parecen atribuir a la educación escolarizada posibilidades antirracistas.

De la escuela se dicen muchas cosas; que sirve para la reproducción de las estructuras sociales de dominación y las desigualdades, como lo señalaran P. Bourdieu y J.-C. Passeron. Cómo contribuye a la subordinación de los saberes populares y es una institución del poder, por tanto, bien valdría la pena pensar en sociedades desescolarizadas, como lo defendiera I. Illich hace cuatro décadas, o ahora G. Esteva, quien afirma que "resistir la escuela y abandonar la educación implica ampliar sustantivamente la dignidad de los hombres y mujeres ordinarios y desafiar todos los sistemas políticos y económicos existentes" (Esteva, 2011: 172).

Otras voces encuentran que en ella se enseña y se recrea el pensamiento colonial, la negación de la diversidad y el epistemicidio, o el asesinato de las epistemologías que no encajan con el pensamiento occidental. Además de nuevas tendencias favorables al análisis de las escuelas como instrumentos de dominación colonial, pero también como espacios de resistencias y de construcción de comunalidad (Maldonado, 2000), siguen permeando en los colectivos docentes perspectivas críticas heredadas de J. Dewey que consideran que la escuela encierra posibilidades democratizadoras, así como de F. Ferrer Guardia que veía un potencial libertario en su propuesta de escuela moderna, y también de $\mathrm{C}$. Freinet que propuso técnicas que inspiran pedagogías cooperativas más actuales. 
Además, las sociologías actuales de la educación comparten a menudo la idea según la cual la escuela puede producir y produce las experiencias escolares que la sociedad le encomienda (Dubet y Martuccelli, 1998). Un atributo semejante subyace en las ideas heredadas de P. Freire, para las cuales bastaría con hacer de la educación un acto consciente para garantizarle posibilidades emancipadoras en varios sentidos. También se ha dicho que la escuela abriga posibilidades antirracistas. Es posible. Algunas experiencias alternas en el sistema educativo mexicano, y las que se desarrollan fuera de ella, lo están testificando.

\section{Los desafíos antirracistas de la escuela}

En México no todas las escuelas tienen los mismos imperativos antirracistas, porque tampoco viven el racismo de la misma manera. Los contenidos y las prácticas del racismo del México mestizo en las escuelas generales en donde asisten mayoritariamente los hijos de familias mestizas, es un racismo, confortable a profesores y a escolares, que se practica generalmente en contra de quienes tienen otros orígenes y no en contra de los mestizos. En cambio, el racismo mestizo-filico es de efectos devastadores entre los niños y niñas, maestros y comunidades afrodescendientes e indígenas. Es verdad que en ambos casos se practica el racismo, y que los contenidos están afectados por enunciados que lo son invariablemente; ya sea en forma explícita o de manera oculta, y que en uno y otro contexto depende de los maestros que tales enunciados racistas y prácticas se ejecuten. Más aún, parece que es incontrovertible que en ambos casos sea la figura de los profesores la que conlleve la responsabilidad principal de que el racismo tenga lugar en la escuela. Esto obedece a que en las escuelas de educación básica las decisiones las toman fundamentalmente los profesores. De ellos depende que los contenidos racistas sean ejecutados o no. Con las prácticas racistas algo semejante ocurre, aunque en su descargo se puede decir que no todo lo que sucede en la esfera de las interacciones está sujeto al control de los profesores. De cualquier modo, lo cierto es que son las escuelas del subsistema indígena en donde parece más crudo y brutal el racismo.

La consulta inédita en el país del Instituto Nacional para la Evaluación de la Educación (INEE), en 2015, dio a conocer la opinión de las comunidades indígenas sobre la educación que reciben. Entre varios aspectos que cubren sus opiniones, en dicha consulta los indígenas declaran que las escuelas los discriminan y excluyen sus conocimientos, sus formas de organización y sus cosmovisiones. Esta apreciación es ampliamente compartida de una comunidad a otra. Se quejan en su mayoría de sus profesores, lamentan que estos no tengan la sensibilidad que el caso amerita. Los ven como los ejecutores de una acción oficial que alienta el desarraigo de sus hijos. La consulta concedió la oportunidad a los profesores de conocer las opiniones recogidas. En una especie de derecho de réplica, ellos reconocen que no siempre han podido reparar su desempeño discriminatorio

y excluyente hacia las comunidades. En cambio, sugieren que frente a lo que hace la escuela, son las comunidades las que a menudo se autoexcluyen y marginan. 
En las escuelas generales, como en las indígenas, la posibilidad de actuar contra el racismo depende en mucho de los colegios de profesores. Si los maestros logran hacerlo consciente, y además pueden reconocer su intervención para modificar la realidad, entonces todo podría cambiar. Pero la experiencia ha demostrado que esto no es cosa sencilla. Como lo verificó J. Aguilar Nery (2012) en un ejercicio de investigación al respecto, los maestros aprendieron a lo largo de su vida y de su formación que la diferencia racial existe, es un hecho, y que es legítimo clasificar a los humanos de esa manera. Por tanto, en su modo de pensar, el racismo puede estar normalizado y radicado en su inconsciente como un dispositivo clasificatorio natural del que se echa mano cada que hace falta hacerlo, respondiendo tan sólo a los mandatos del gobierno interno, es decir, de los imperativos biopolíticos que autorregulan casi inconscientemente muchas de sus acciones. Entonces, uno de los desafíos mayores en la tarea antirracista consistiría en primer lugar en la toma de conciencia del significado del racismo y sus implicaciones. Esto conllevaría invariablemente a la necesidad de aprender qué es el racismo, cómo se manifiesta y qué efectos provoca, para plantearse la necesidad de eliminar de raíz toda la normalización que goza en las subjetividades de los profesores y, consecuentemente, en las conductas que asumen en su tarea docente. La auto-vigilancia que deben practicar los profesores y sobre sus acciones, así como la vigilancia que deben ejercer sobre los contenidos escolares, se vuelven decisivas en esta tarea.

\section{Consideraciones finales}

\section{Los niveles probables de acción antirracista escolar}

\section{La acción local}

Por lo antedicho es claro que, para el antirracismo escolar, los casos pueden multiplicarse tantas veces como escuelas existan o como proyectos locales o regionales puedan ser creados con ese propósito. De esto, hay algunos ejemplos dignos de ser mencionados.

En el contexto de la guerra de Guatemala en las décadas de los años ochenta y noventa, las Comunidades de Población en Resistencia fomentaron una educación multicultural impartida en condiciones precarias por "promotores" indígenas formados en los movimientos cooperativos y campesinos. Durante el conflicto armado y la "resistencia", las prácticas cotidianas recrean otros modos de entender la educación política impulsada por los movimientos sociales, como prácticas autónomas e independientes de las estructuras públicas. El joven promotor está dispuesto a asumir la tarea pedagógica como una militancia "pero esta voluntad es socavada por un poder gubernamental que sigue siendo racista con el indígena, ya que está acostumbrado a procesos coloniales y dominadores", a pesar de que su formación durante la resistencia "fortificó el cuadro de maestros y maestras que desde su autonomía están visibilizando un movimiento social intercultural" (Muñoz Sánchez, 2015: 122). En cierta medida, parece que movilizaciones de este tipo representan una condición para el fortalecimiento de las capacidades de acción y de reflexión de los actores comunitarios implicados en controlar que la educación no reproduzca las jerarquías generadas por la racialización de las desigualdades. 
En la lucha por una educación antirracista es fundamental generar también las condiciones locales para la autoría indígena y afrodescendiente de los materiales pedagógicos, apoyada en la colaboración con los blancomestizos, "como un ejercicio ciudadano y político activo que subvierte el verticalismo del Estado monocultural, para que sus actores e instituciones modifiquen su etnocentrismo y aprendan -como busca el movimiento zapatista en México- a mandar obedeciendo" (Bertely, 2011: 42). Las aportaciones de la investigación educativa a nivel local pueden coadyuvar a determinar de manera minuciosa cuáles son las condiciones interactorales que favorecen e impiden la emergencia multisituada de experiencias de educación antirracista. Es a partir de iniciativas novedosas de capacitación crítica, con cursos y talleres dedicados a la formación de adultos (no solo docentes), que se puede vislumbrar el combate eficaz contra las discriminaciones racistas en la educación. La enseñanza generalizada de las historias y los derechos colectivos de los pueblos indígenas puede considerarse como un instrumento contundente para quebrantar la cultura del desprecio que predomina en la sociedad (Baronnet, 2013), la cual impide que los pueblos originarios gocen de derechos al acceso y a la permanencia en la escuela, así como a la creación y a la administración autónoma de centros educativos para la defensa local de territorios amenazados a nivel global.

\section{La acción global}

A la acción local antirracista consideramos que debe corresponder una acción global que invariablemente apuntaría a los planes de estudio, que es desde donde se derivan los libros de texto y sus contenidos. A la vigilancia a la que puede someterse la acción docente, que ya apuntábamos, habría que sumar una intervención semejante en los contenidos educativos. El currículum educativo merece una acción profiláctica que elimine lo implícito y lo explícito que tiene de racismo. Si para promover la laicidad educativa fue decisivo actuar para eliminar toda referencia religiosa en los planes de estudio, y en la práctica docente, algo semejante puede hacerse con el tema que aquí nos ocupa. Si como nos lo recuerda muy bien J. Habermas (1999), el proceso de secularización social -que separó a la iglesia de los asuntos del Estado y sus instituciones- tuvo que enseñarse y aprenderse, y ello nos remite invariablemente a la escuela, el antirracismo podría seguir una senda semejante y alcanzar una solución análoga. Entonces podemos formular como recomendación la intervención en el currículum educativo tanto como la promoción para que esto tenga correspondencia con una acción docente orientada a ese fin.

Por los casos que aquí hemos reseñado brevemente, es posible que el cambio pueda resultar si los maestros actúan proactivamente en contra del racismo en la escuela, a pesar de la preponderancia de algunos planes de estudios invadidos de racismo, pero no debe descansar completamente sobre los hombros del profesorado. De la misma manera, no se puede acometer la limpieza del currículum educativo en aras de eliminar el racismo desde la escuela, obviando el peso que tiene la acción docente. Al respecto, el profesor J. C. Callirgos (1993), experto en el tema del racismo 
en la educación del Perú, señalaba que podría tenerse un plan de estudios que sostuviera una cultura escolar ideal libre de racismo, pero eso no podría garantizar nada, porque la escuela siempre corre el riesgo de ser presa fácil de una cultura escolar realmente existente, plena de un racismo, que se suele imponer sin ningún obstáculo. Nuestro consejo entonces lo radicamos en dos medidas sincronizadas: (1) la revisión y limpieza de los planes de estudio, en un sentido profiláctico que los depure de toda fuente de racismo, y (2) el esmero que merece una formación docente con ese mismo propósito. Mientras transcurre la espera para que eso suceda, lo más conveniente será confiar en la capacidad de los educadores. Ellos pueden bloquear al racismo, porque hasta ahora son la parte que vivifica la acción educativa, y son, muy a pesar de la apreciación oficial que se tiene de ellos, la fuente más genuina para esperar que algún día las cosas en esta materia realmente cambien.

\section{Bibliografía}

Aguilar Nery, J. (2012). "Diferencia racial en docentes de educación básica de Tijuana y Tecate. Un estudio exploratorio". En: Culturales, vol. 8, núm. 15, Universidad Autónoma de Baja California, pp. 47-80.

Balibar, E. e I. Wallerstein. (1990). Race, nation, classe. Les identités ambigües. París: La Découverte.

Baronnet, B. (2013). "Racismo y discriminaciones en el sistema educativo mexicano". En: Ascencio, Gabriel (coord.). Teoría y práctica de la educación intercultural en Chiapas. México: PROIMMSE-IIA-UNAM, pp. 63-79.

Basave, A. (1992). México mestizo: análisis del nacionalismo mexicano en torno a la mestizofilia. México: Fondo de la Cultura Económica.

Bertely, M. (2011). "Aproximación a la discriminación con énfasis en el tratamiento ciudadano". En: López, N. (coord.). Escuela, identidad y discriminación. Buenos Aires: IIPE-UNESCO, pp. 27-65.

Bourdieu, P. (1990). Sociología y cultura. México: Grijalbo.

Callirgos, J. C. (1993). "La discriminación en la socialización escolar". En: Separata. Lima: Fondo Editorial de la Pontificia Universidad Católica del Perú. Disponible en: http://www.cholonautas.edu.pe/modulo/upload/Callirgos.pdf

Carlos Fregoso, G. (2016). "Racismo y educación superior: estudiantes indígenas en dos centros universitarios de la Universidad de Guadalajara, Jalisco, en un marco de políticas interculturales". Tesis de Doctorado en Investigación Educativa, Xalapa: Universidad Veracruzana.

Castellanos Guerrero, A. (2012). "La construcción del Otro en ciudades mexicanas. Del pensamiento liberal y la exclusión neoliberal”. En: Castellanos, Alicia y Gisela Landázuri (coords.). Racismo y otras formas de intolerancia de Norte a Sur en América Latina. México: UAM-I/ Juan Pablos Editor, pp. 99-124. 


\section{Racismo y escuela en México: Reconociendo la tragedia para intentar la salida}

Castellanos Guerrero, A. (coord.) (2003). Imágenes del racismo en México. México: Plaza y Valdés.

Cejas, M. I. (coord.) (2004). Leer y pensar el racismo, Guadalajara. México: UdeG/UAM-X/Municipio de Zapopan.

Croizet, J. C. (2013). "On the Fatal Attractiveness of Psychology: Racism of Intelligence in Education". En: Smeyers, P. y M. Depaepe (eds.). Educational Research: The Attraction 33 of Psychology, Educational Research 6, Springer, pp. 33-51.

Díaz-Couder, E., E. Gigante y G. Ornelas (coords.) (2015). Diversidad, ciudadanía y educación. Sujetos y contextos. México: Universidad Pedagógica Nacional.

Dubet, F. y Martuccelli, D. (1998). En la escuela. Sociología de la experiencia escolar. Madrid: Losada.

Esteva, G. (2011). “Más allá de la educación”. En: Meyer, L. y B. Maldonado (coords.). Comunalidad, educación y resistencia indígena en la era global. Oaxaca: CSEIIO, pp. 159-174.

Gall, O. (2004). "Identidad, exclusión y racismo: reflexiones teóricas y sobre México". En: Revista Mexicana de Sociología 66(2). México: Instituto de Investigaciones Sociales-UNAM, pp. 221259.

(2007). "Racismo y modernidad: preguntas y planteamientos". En: Gall, O. (coord.). Racismo, mestizaje y modernidad: visiones desde latitudes diversas. México: UNAM, pp. 63-88.

Gallo, S. (Org.) (2014). As diferentes faces do racismo e suas implicações na scola. Campinas: Leitura Crítica/alb.

Gnade, J. R. (2008). "Raza, racismo y educación escolar en México". Tesis de doctorado en Estudios Latinoamericanos. México: FFyL-UNAM.

Gómez Izquierdo, J. (2005). Los caminos del racismo en México. México: Plaza y Valdés/BUAP.

Gómez Izquierdo, J. (2008). El camaleón ideológico. Nacionalismo, cultura y política en México durante los años del presidente Lázaro Cárdenas (1934-1940). México: Benemérita Universidad Autónoma de Puebla/Instituto de Ciencias Sociales y Humanidades.

Habermas, J. (1999). La inclusión del otro. Barcelona: Paidós.

Hamel, E. et al. (2004). “'Qué hacemos con la castilla' La enseñanza del español como segunda lengua en un currículo intercultural bilingüe de educación indígena”. En: Revista Mexicana de Investigación Educativa. Sección temática: Educación intercultural, IX, (20), México: Universidad Autónoma Metropolitana/Consejo Mexicano de Investigación Educativa, pp. 83107.

Hernández Rosete, D. (en prensa). Creencias sobre ausentismo y rezago escolar de niños indígenas bilingües en escuelas de La Merced. México.

Iturriaga, E. (2011). "Las élites de la ciudad Blanca: racismo, prácticas y discriminación étnica en Mérida, Yucatán". Tesis de doctorado en el Instituto de Investigaciones Antropológicas. México: FFyL-UNAM. 
Jordá Hernández, J. (2000). Proceso de formación docente y propuesta pedagógica en las Lep y lepmi'90. México: Universidad Pedagógica Nacional.

Klein, M. G. et al. (2014). "Desde Chiapas: Criterios básicos para la exigencia de pertinencia cultural y lingüística en la educación”. En: Incidencia Civil en Educación A.C. Desenmascarar la discriminación. La violencia del sistema educativo mexicano hacia los pueblos originarios y las personas con discapacidad. México: ICE A.C., pp. 69-117.

Maldonado Alvarado, B. (2000). Los indios en las aulas. Dinámicas de dominación y resistencia en Oaxaca. Oaxaca: Centro INAH.

Masferrer, C. (2012). En: Gómez Quintero, Natalia, "Ven discriminación en libros de la SEP". El Universal. México, domingo 26 de febrero de 2012, sección 'Nación”. Recuperado en: http:// www.eluniversal.com.mx/nacion/194275.html (consultado 17 de abril de 2016).

McCarthy, C. (1993). Racismo y curriculum. La desigualdad social y las teorías y políticas de las diferencias en la investigación contemporánea sobre la enseñanza. Madrid: Morata.

Mejía, C. y S. Sarmiento (1987). Lucha indígena. Un reto a la ortodoxia. México: Instituto de Investigaciones Sociales-UNAM / Siglo XXI.

Mena, M. I. (2011). "Indagando el racismo, interpelando al docente: estudio de caso sobre manifestaciones de racismo y discriminación racial en las escuelas públicas de Bogotá". En: López, N. (coord.). Escuela, identidad y discriminación. Buenos Aires: IIPE-UNESCO, pp. 149-164.

Menéndez, E. L. (enero-junio 2001). "Biologización y racismo en la vida cotidiana". En: Alteridades, 11(21). México: UAM-I, pp. 5-39.

— (2016). "Los racismos son eternos". En: Conferencia Guillermo Bonfil Batalla. México: Programa PUIC, UNAM, 10 de marzo de 2016.

Molina Ludy, V. (2000). "La ideología subyacente en la discriminación hacia los pueblos indios". En: Barceló, R., M. A. Portal y M. Sánchez (coords.). Diversidad étnica y conflicto en América Latina. El indio como metáfora en la identidad nacional. Vol. II. México: UNAM / Plaza y Valdés, pp. 147-174.

Moreno Figueroa, M. (2010). "Distributed Intensities: Whiteness, Mestizaje and the Logics of Mexican Racism”. Ethnicities 10, pp. 387-401.

Muñoz Cruz, H. (1987). Funciones sociales y conciencia del lenguaje. Xalapa: Universidad Veracruzana.

Muñoz Sánchez, P. (2015). "Movimientos sociales surgidos por una Educación Indígena Intercultural: casos en Guatemala y México". En: Gehrig, R. y P. Muñoz Sánchez (coords.). Educación, identidad y derechos como estrategias desarrollo de los pueblos indígenas. Murcia: UCAM, pp. 114-132.

Navarrete, F. (2016). "Alfabeto racista mexicano I". En: Horizontal, 3 de marzo de 2016. Entrada A de Aspiracional, disponible en: http://horizontal.mx/alfabeto-racista-mexicano-1/ 
París Pombo, M. D. (2002). "Estudios sobre el racismo en América Latina”. En: Política y Cultura (17). México: Universidad Autónoma Metropolitana, Unidad Xochimilco, pp. 289-310.

Pérez Ruiz, M. L. y A. Argueta Villamar (2015). "Jóvenes indígenas como promotores culturales. Dos experiencias mexicanas (1951-1992)”. En: Pérez Ruiz, M. L., V. Ruiz Lagier y S. Velasco Cruz (coords.) Interculturalidad(es). Jóvenes indígenas: educación y migración. México: Universidad Pedagógica Nacional, pp. 27-75.

Quijano, A. (2000). "Colonialidad del poder, eurocentrismo y América Latina". En: Lander, Edgardo (comp.). La colonialidad del saber: eurocentrismo y ciencias sociales. Perspectivas latinoamericanas. Buenos Aires: CLACSO/UNESCO.

Ramírez, E. (2006). Educación indígena en México. México: UNAM.

Rebolledo, Nicanor (2010). "Indigenismo, bilingüismo y educación bilingüe en México: 19392009". En: Velasco Cruz, S. y A. Jablonska (coords.) Construcción de políticas educativas interculturales en México: Debates, tendencias, problemas, desafios. México: Universidad Pedagógica Nacional, pp. 113-157.

Saldívar, E. (2012). "Racismo en México: apuntes críticos sobre etnicidad y diferencias culturales". En: Castellanos, A. y G. Landázuri (coords.) Racismo y otras formas de intolerancia de Norte a Sur en América Latina. México: UAM-I/Juan Pablos Editor, pp. 49-98.

Urías Horcasitas, B. (2007). Historias secretas del racismo en México (1920-1950). México: Tusquets.

Van Dijk, T. (2007). Racismo y discurso en América Latina. Barcelona: Gedisa.

Velasco Cruz, S. (2015). "La escolaridad de los docentes indígenas de México". Revista Interamericana de Educación de Adultos 37(2), CREFAL, pp. 85-102.

Velasco Cruz, S. (2016). "Racismo y educación en México". Revista Mexicana de Ciencias Políticas y Sociales. UNAM, (61)226, México: UNAM, pp. 309-338.

Wieviorka, M. (2009). Racismo, una introducción, Madrid: Gedisa. 